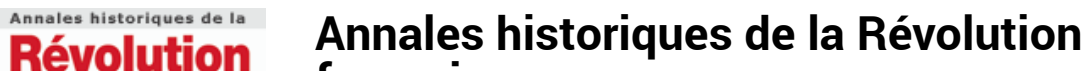

française française

339 | janvier-mars 2005

Varia

\section{Histoire du Salon de peinture}

\section{Michel Biard}

\section{(2) OpenEdition \\ Journals}

Édition électronique

URL : https://journals.openedition.org/ahrf/2160

DOI : 10.4000/ahrf.2160

ISSN : 1952-403X

Éditeur :

Armand Colin, Société des études robespierristes

Édition imprimée

Date de publication : 1 mars 2005

Pagination : 192-194

ISSN : 0003-4436

\section{Référence électronique}

Michel Biard, « Histoire du Salon de peinture », Annales historiques de la Révolution française [En ligne], 339 | janvier-mars 2005, mis en ligne le 24 avril 2006, consulté le 24 avril 2022. URL : http:// journals.openedition.org/ahrf/2160 ; DOI : https://doi.org/10.4000/ahrf.2160

Ce document a été généré automatiquement le 24 avril 2022.

Tous droits réservés 


\title{
Histoire du Salon de peinture
}

\author{
Michel Biard
}

\section{RÉFÉRENCE}

Gérard-Georges Lemaire, Histoire du Salon de peinture, Paris, Klincksieck, 2004, 256 p., ISBN 2-252-03375-4, $14 \mathrm{e}$.

1 L'ouvrage est un petit essai de synthèse sur l'histoire du Salon, étudiée de ses origines, au XVII ${ }^{\mathrm{e}}$ siècle, aux années de son déclin progressif au cours du xix ${ }^{\mathrm{e}}$ siècle. Il comporte un index qui pourra rendre quelque service, mais, en revanche, la bibliographie est d'une grande légèreté. Pour ne citer qu'un exemple particulièrement flagrant, elle ne comprend pour la biographie et l'œuvre de David qu'une seule référence. Qui plus est, celle-ci est réservée à un ouvrage d'É. Delécluze, donné ici dans sa réédition de 1983, sans aucune mention de l'édition de... 1855 ! Que chacun puisse être libre d'apprécier l'ouvrage de Delécluze, nul ne le contestera, mais comment peut-on “oublier", outre les références aux grands catalogues d'exposition, les noms d'A. Schnapper, Ph. Bordes, D. L. Dowd, D. Johnson ou encore W. E. Roberts, pour ne mentionner que quelques travaux sur David et son temps (et s'en tenir aux langues française et anglaise) ? Il sera toujours possible d'objecter que les objectifs de l'ouvrage nécessitaient une seule référence, mais auquel cas pourquoi diable choisir Delécluze?

2 Le livre est organisé autour de cinquante questions successives et respecte un ordre chronologique. Ainsi peut-on trouver parmi les questions : «Quel fut l'enjeu du Salon de 1789 ?»; "Quelle est la spécificité des Salons pendant la crise révolutionnaire?»; ou encore "Comment le Salon évolue-t-il sous le Consulat et l'Empire? »; sans oublier certains titres voulus comme "accrocheurs", tel «Un Thermidor du pinceau?». La période révolutionnaire est abordée dans le troisième chapitre de cet ouvrage qui en compte sept, sous le titre «De la tourmente révolutionnaire à la Restauration (1789-1830) ( (avec une trentaine de pages).

3 Le lecteur pourra trouver au fil de ces pages quelques références utiles sur la naissance des Salons, dès lors que les statuts de l'Académie portaient (en 1663) que, à l'occasion 
de l'Assemblée générale, les artistes seraient invités à apporter "quelque morceau de leur choix pour servir à décorer le lieu de l'Académie pour quelques jours seulement, et après les remporter si bon leur semble ». Du premier Salon tenu au printemps 1667 à celui de 1699 installé dans la Grande Galerie du Louvre et assorti pour la première fois d'un livret, on suivra les évolutions de cette institution qui s'impose peu à peu au détriment de ses concurrents potentiels (le «Salon de la jeunesse » où, lors des foires, des artistes exposent leurs œuvres «sans le moindre apprêt, au milieu de toutes sortes de choses, même de victuailles"; mais pour lequel des peintres de renom, comme Chardin, n'hésitent pas à proposer leurs travaux dans les années 1720-1730). Même si, en effet, d'autres personnages et d'autres lieux organisent des expositions, le Salon devient à partir de la fin des années 1730 l'Exposition, et son succès ne fait que croître tout au long du siècle, suscitant sans cesse des nouveautés comme celles introduites par Chardin. Grand maître de l'accrochage de 1766 à 1773, il n'hésite point à mettre côte à côte des œuvres en rapport, ce qui fait écrire à Diderot, dans son Salon de 1769 : «Ce tapissier Chardin est un espiègle de première force, il est enchanté quand il a fait de bonnes malices; il est vrai qu'il met à portée de s'éclairer par des comparaisons rapprochées des artistes entre lesquels il établit une lutte tout à fait périlleuse ». Si la critique se développe dès le milieu du siècle (des Réflexions sur quelques causes de l'état présent de la peinture en France, publiées sous couvert de l'anonymat en 1747, aux Salons de Diderot de 1759 à 1781), le livret officiel donne quant à lui l'occasion de publier, en concurrence peu loyale, de multiples brochures et feuilles éphémères destinées à brocarder tel ou tel artiste, et qui atteignent parfois leur but (un observateur note ainsi, en 1785 : «On a vu des particuliers qui, après avoir commandé le Tableau exposé, ne voulaient plus le prendre, après lecture des critiques et plaider pour ne plus y être forcés »). D'autres citations pourraient encore être ajoutées afin de montrer que l'ouvrage de Gérard-Georges Lemaire est, à défaut d'être une étude de fond sur les années 1667-1789, susceptible d'apporter d'intéressants détails sur tel ou tel Salon, et évidemment sur les évolutions de la critique, avec les règles exposées par Diderot: "Qu'est-ce que le goût? Une facilité acquise, par des expériences réitérées, à saisir le vrai ou le bon, avec la circonstance qui le rend beau, et d'être promptement et vraiment touché ». En revanche, les quelques pages consacrées à la période révolutionnaire n'apporteront pas grand chose au lecteur.

D'une part, Jean-François Heim, Claire Béraud et Philippe Heim ont publié en 1989 un ouvrage de référence sur Les Salons de peinture de la Révolution française (1789-1799) qui est utilisé par Gérard-Georges Lemaire au prix d'une bien pâle copie. D'autre part, les pages rédigées par ce dernier auteur ne laissent pas de surprendre. On lit ainsi successivement (p. 65) que d'Angiviller décide « de supprimer purement et simplement le Salon de 1791 », puis (p. 67) que « Talleyrand-Périgord est chargé d'organiser le Salon de 1791 ». S'il est possible d'admettre qu'il s'agisse là simplement d'une confusion liée à l'organisation du livre en "questions", force est toutefois de constater dans l'ouvrage la répétition de telles phrases pour le moins contradictoires (la campagne pour la suppression des Académies est ainsi, elle aussi, décrite de manière totalement confuse). Mais, au-delà de ce manque de clarté parfois gênant, l'ouvrage comprend hélas des approximations ou des silences étonnants. Pour ne citer que trois exemples, peut-on commenter le Triomphe du Peuple français, ou le 10 Août d'Hennequin avec de simples observations sur les dimensions de la toile? Peut-on simplement dire du Retour de Marcus Sextus, de Guérin qu'il "obtient un certain succès", là où l'œuvre gêne politiquement par sa référence implicite aux «émigrés rentrés ", à tel point qu'en 
octobre 1799 David, Regnault et d'autres artistes signent une pétition pour soutenir cette œuvre auprès du Directoire ? Peut-on écrire à propos du Courage héroïque du jeune Desilles, de Le Barbier, qu'avec cette œuvre « on s'attache [...] à mettre en évidence [...] les horreurs de la Révolution »? Gageons qu'en 1795, il y avait bien d'autres scènes à utiliser que l'affaire de Nancy en 1790 pour dénoncer lesdites «horreurs »! Enfin, puisque j'ai commencé ce compte rendu en évoquant David, force est de l'achever en livrant quelques-uns des jugements portés à son propos par l'auteur. Que «l'ambitieux David " ne se soit soucié dès 1789 que de parvenir "à ses fins ", passe encore, tant est banale l'appréciation... mais comment ne pas rester consterné devant les phrases suivantes: David est "premier secrétaire des Jacobins»; "Pour mieux peser sur la décision de la représentation de la Nation, David est entré en politique et est élu député »; il « participe aux délibérations du Comité de sûreté générale »; après « le coup d'État du 9 Thermidor ", il « sauve sa tête in extremis et, en tacticien consommé, se rallie à point nommé à Bonaparte »... ajoutons que trois petites lignes (p. 66) séparent le 9 Thermidor du ralliement en question!

Quiconque connaît un peu la période révolutionnaire ne peut que frémir et du coup se poser la question de la valeur de cette moitié de l'ouvrage qui reste encore à découvrir au-delà de la page 92, proposant au lecteur un parcours au fil du XIX siècle, des polémiques liées à l'apparition des différents courants picturaux aux Salons concurrents (dont le fameux Salon des refusés). Comment ne pas craindre la répétition de semblables erreurs pour ces autres décennies? Je n'en dirai rien dans le cadre des A.H.R.F., mais le constat semble bien hélas toujours le même : vouloir toucher le "grand public" est une chose, rédiger un manuel ou un essai en donnant la "substantifique moelle » tout en conservant un contenu scientifique digne de ce nom en est décidément une autre. 